\title{
Pneumothorax as a complication of ESD
}

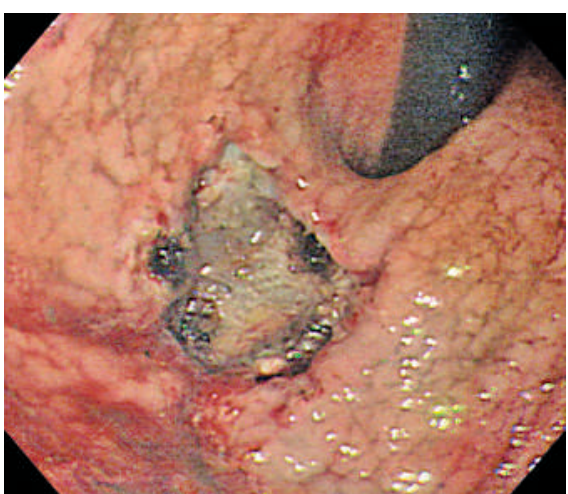

Figure 1 One-piece mucosal resection by endoscopic submucosal dissection with insulated-tip knife was performed for early gastric cancer located in the cardia. Bleeding during endoscopic submucosal dissection was controlled by epinephrine injection with electrocoagulation.

Endoscopic submucosal dissection (ESD) is a useful alternative to surgery for the treatment of selected cases of early gastric cancer (EGC) [1-3]. The two main complications associated with ESD are perforation and bleeding.

A 66-year-old woman with EGC was admitted to our hospital for ESD. The EGC (adenocarcinoma) lesion was type IIc, was $15 \mathrm{~mm}$ in diameter, and was located in the cardia. No lymph node metastasis was seen with stomach computed tomography. ESD was performed using an Olympus XQ-240 video endoscope with an insulated-tip knife (Figure $\mathbf{1}$ ). Immediately following ESD, the patient complained of dyspnea and abdominal pain with distension. A chest radiograph revealed pneumoperitoneum and left pneumothorax (Figure 2). The patient underwent pigtail catheter insertion into the left pleural space with oxygen inhalation, and was treated with a regimen consisting of fasting plus the administration of an intravenous proton pump inhibitor and antibiotics. Five days later, the pneumothorax and pneumoperitoneum were improved, and a follow-up endoscopy showed postESD ulcer without bleeding or further complications. Pathologically, the lateral resection margin was clear but the tumor had invaded the submucosa. Because the patient elected not to undergo additional

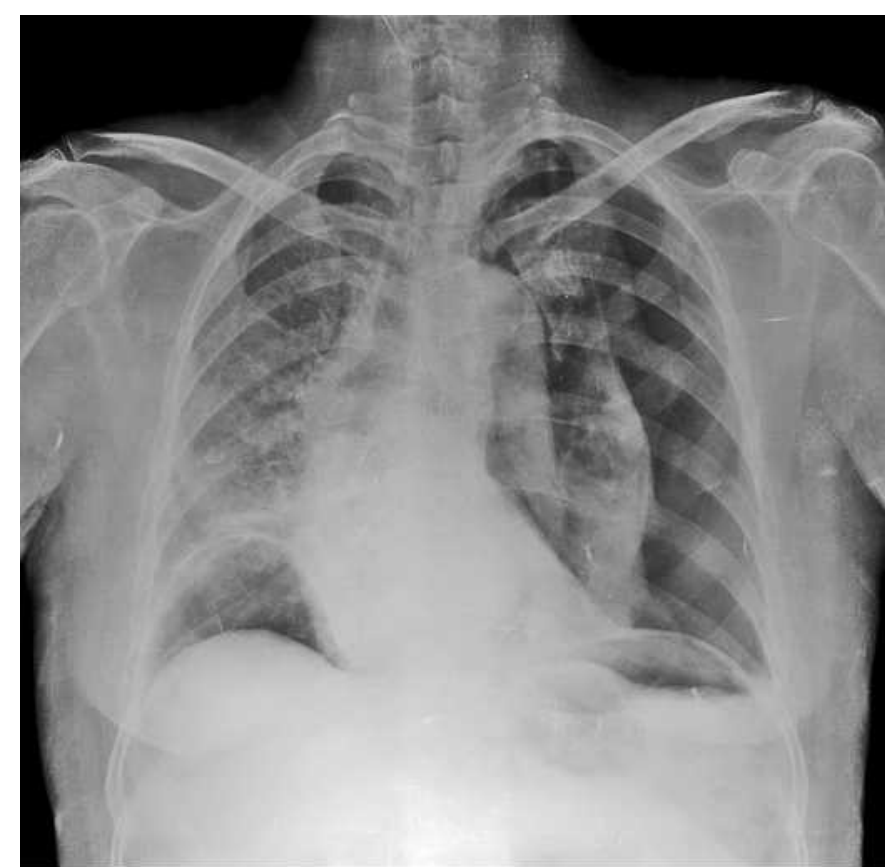

Figure 2 Chest radiograph after endoscopic submucosal dissection showing free air at both the subdiaphragm and left pneumothorax, with right deviation of the trachea, mediastinum, and heart, along with haziness of the right lung.

surgery, she was discharged 7 days after perforation. Six weeks later, a follow-up biopsy for the post-ESD ulcer scar revealed no evidence of malignancy.

The rate of perforation and immediate bleeding in the cardia and the upper portion of the gastric body during endoscopic resection is higher than in the lower third of the stomach $[3,4]$. Gastric perforations after ESD have predominantly been successfully treated with endoscopic clipping, intubation of the nasogastric tube, and administration of antibiotics without surgery $[1,5]$. Although most post-ESD perforations can be conservatively treated, endoscopists must keep in mind that pneumothorax can develop during ESD in the cardia, and that a careful procedure is essential.

\section{Endoscopy_UCTN_Code_CPL_1AH_2AZ}

C. S. Jang, D. K. Park, K. A. Kwon, S. K. Yu, Y. K. Kim

Department of Gastroenterology and Hepatology, Gachon University Gil Medical Center, Incheon, South Korea.

\section{References}

${ }^{1}$ Ono H, Kondo H, Gotoda T et al. Endoscopic mucosal resection for the treatment of early gastric cancer. Gut 2001; 48: 225-229

${ }^{2}$ Lee JH, Yoon JH, Kim BG et al. Endoscopic mucosal resection as a curative treatment of early gastric cancer. Korean J Gastrointest Endosc 1996; 16: 928-934

3 Ohkuwa M, Hosokawa N, Boku N et al. New endoscopic treatment for intramucosal gastric tumors using an insulated-tip diathermic knife. Endoscopy 2001; 33: 221 - 226

${ }^{4}$ Oda I, Gotoda T, Hamanaka H et al. Endoscopic submucosal dissection for early gastric cancer: technical feasibility, operation time and complications from a large consecutive cases. Dig Endosc 2005; 17: 54-58

${ }^{5}$ Minami S, Gotoda T, Ono $\mathrm{H}$ et al. Complete endoscopic closure of gastric perforation induced by endoscopic resection of early gastric cancer using endoclips can prevent surgery. Gastrointest Endosc 2006; 63: $596-$ 601

\section{Corresponding author}

\section{K. Park, MD}

Department of Gastroenterology and Hepatology

Gachon University Gil Medical Center . 1198 Guwol-dong Namdong-gu · 405-760 Incheon · South Korea

Fax: $\quad+82-32-460-3408$

Email: pdk66@gilhospital.com 